\title{
Thermal Inactivation of Inoculum of Two Phytophthora Species by Intermittent Versus Constant Heat
}

\author{
Fumiaki Funahashi† and Jennifer L. Parke
}

Department of Crop and Soil Science, Oregon State University, Corvallis 97331.

Accepted for publication 26 January 2018.

\begin{abstract}
Research on solarization efficacy has examined the critical temperature and minimum exposure time to inactivate soilborne pathogens. Most mathematical models focus on survival of inoculum subjected to a constant heat regime rather than an intermittent heat regime that better simulates field conditions. To develop a more accurate predictive model, we conducted controlled lab experiments with rhododendron leaf disks infested with Phytophthora ramorum and P. pini. Focused in vitro experiments with $P$. ramorum showed significantly longer survival of inoculum exposed to intermittent versus constant heat, indicating that intermittent heat is less

damaging. A similar trend was observed in soil. Damage was evaluated by comparing the reduction in subsequent survival time of inoculum subjected to different intensities of sublethal heat treatments. Inoculum exposure to continuous heat reflected an increasing rate of damage accumulation. Multiple sublethal heat events resulted in a constant rate of damage accumulation which allowed us to calculate total damage as the sum of damage from each heat event. A model including a correction for an intermittent heat regime significantly improved the prediction of thermal inactivation under a temperature regime that simulated field conditions.
\end{abstract}

Solarization is a potential management tool for soilborne pathogens. It has been recently shown to be effective for Phytophthora ramorum in container nursery beds (Funahashi and Parke 2016). $P$. ramorum is a quarantine pathogen and causes sudden oak death. The pathogen is spread by movement of nursery plants (Goss et al. 2009), and there were 561 nursery detections in the United States between 2001 and 2014 (USDA-APHIS 2015). Once nursery beds become infested by the pathogen, they are extremely challenging to disinfest, and many nurseries are found to be recurrently positive in the test for the pathogen (USDA-APHIS, unpublished). Although soil solarization can be effective for disinfesting soil, an accurate predictive model is required to determine the feasibility and the appropriate duration of solarization treatment at different locations and soil depths.

Thermal inactivation (death) curves have been established to predict pathogen mortality in response to elevated temperature (Gamliel and Katan 2012). One of the most popular approaches is the degree-hour concept, in which mortality is related to the accumulated time of exposure above a certain threshold temperature (Shlevin et al. 2003). The degree-hour model has been proposed in various studies as a tool for evaluating the effectiveness of thermal inactivation of pathogens (Chellemi et al. 1994; Lopez-Herrera et al. 1994, 1997; Walkey and Freeman 1977). However, this model is not always successful because the degree-hour concept is empirical and it gives equal weight to all temperatures above a threshold temperature (Shlevin et al. 2003). Another popular approach is a first-order kinetics concept (e.g., Z-value model or Arrhenius model) (Corradini and Peleg 2006; Fujikawa and Itoh 1998; Sasanelli and Greco 2000) and Weibull model (Peleg and Cole 1998; Peleg and Penchina 2000; van Boekel 2002; Weibull 1951), in

†Corresponding author: F. Funahashi; E-mail: funahasf@gmail.com

Funding: Funding for this research was provided by the United States Department of Agriculture Animal and Plant Health Inspection Service under Cooperative Agreement 13-8130-0310-CA.

*The $\boldsymbol{e}$-Xtra logo stands for "electronic extra" and indicates that four supplementary figures are published online.

(c) 2018 The American Phytopathological Society which the rate of decline in a pathogen population is related to a first-order temperature equation. It is also common to build a model using the concept of lethal dose (LD) to indicate the lethality of a given temperature to a proportion of a pathogen population; for example, $\mathrm{LD}_{50}$ (Pullman et al. 1981; Tamietti and Valentino 2001).

With any model, the strategy is to find a simple correlation between important physiological factors (e.g., temperature and water potential) and inactivation (death) of the pathogen. It is fundamental to include temperature in a predictive model as the first factor. However, some noticeable discrepancies have been found and other factors need to be included (Shlevin et al. 2003). It has been shown that many microbes are more heat resistant in drier conditions than in moist conditions (Gamliel and Katan 2012; Russell 2003).

Another important factor is the soil temperature regime. Pathogen propagules are exposed to a diurnal, fluctuating temperature regime during solarization, with highest temperatures achieved in the late afternoon and lowest temperatures by early morning. Models have been commonly constructed based on a cumulative heat effect assumption from lab experiments with constant heat treatments; for example, with Escherichia coli (Fujikawa and Itoh 1998) and a variety of organisms, including Clostridium botulinum, Bacillus stearothermophilus, Salmonella typhimurium, Listeria monocylogenes, E. coli, and Vibrio vulnificus (Peleg and Cole 1998), Bacillus stearothermophilus (Sapru et al. 1993), Aphanomyces cochlioides (Dyer et al. 2007), and theoretical simulation (Corradini and Peleg 2006; Peleg and Cole 1998). However, there is evidence that exposure to fluctuating temperature has significant effects on the pathogen response to heat. Porter (1991) evaluated the effect of intermittent heating of soil ( $6 \mathrm{~h} /$ day over 14 days to temperatures of 30 to $45^{\circ} \mathrm{C}$ ) on the inactivation of Sclerotinia sclerotiorum sclerotia. Constant heat was more effective than intermittent heat for reducing the number of viable sclerotia. Although Coelho et al. (2000) did not conduct a direct comparison between constant versus intermittent heat on the reduction of a $P$. nicotianae population, they reported that $48 \mathrm{~h}$ of constant exposure to $44^{\circ} \mathrm{C}$ was required to reduce the population to below the detection level (1 propagule/g of soil) but, with intermittent heat $(5 \mathrm{~h}$ /day for 15 days), a total of $75 \mathrm{~h}$ of exposure to the same temperature was required. Likewise, only $4 \mathrm{~h}$ of constant heat at $47^{\circ} \mathrm{C}$ was required, as compared with $9 \mathrm{~h}$ of intermittent heat ( 3 days of $3 \mathrm{~h} /$ day). In contrast, there was no 
significant effect of temperature fluctuation on $A$. cochlioides survival in water at $45^{\circ} \mathrm{C}$ ( $4 \mathrm{~h} /$ day) (Dyer et al. 2007). Intermittent heat did not appear to be less effective than continuous heat in a soil experiment with Sclerotium oryzae sclerotia but, rather, appeared to be a little more effective (Usmani and Ghaffar 1986). In our previous field trials, extended survival was observed for $P$. ramorum at the 5-cm depth in nonsolarized plots even though the cumulative hours exposed to high soil temperature should have been adequate to inactivate the pathogen (Funahashi and Parke 2016). Because this is likely due to the combined effects of soil moisture and intermittent heat, it is relevant to assess each effect separately under controlled lab conditions.

The objectives of this study were to (i) compare the effects of constant versus intermittent heat on survival of $P$. ramorum inoculum, (ii) determine whether exposure to sublethal temperatures affected subsequent inoculum survival time, and (iii) determine whether a model predicting pathogen recovery of $P$. ramorum and $P$. pini inoculum would be improved by taking intermittent versus constant heat into account. Although the main focus of this work was $P$. ramorum, we also included $P$. pini Leonian in this study. $P$. pini, previously known as $P$. citricola I (Hong et al. 2011), is a common plant-pathogenic Phytophthora sp. in nurseries (Hong et al. 2008; Olson et al. 2013; Parke et al. 2014). We wanted to know whether $P$. pini and $P$. ramorum respond similarly to a fluctuating temperature regime; if so, $P$. pini could serve as a surrogate for $P$. ramorum in future field trials outside quarantine facilities to validate our model. $P$. pini has been reported to tolerate higher temperatures than does $P$. ramorum (Jung and Burgess 2009; Werres et al. 2001).

\section{MATERIALS AND METHODS}

Phytophthora spp. inoculum. P. ramorum Werres, de Cock \& Man in't Veld isolate Pr-1418886 and P. pini Leonian isolate Pc98517 were used to produce infested leaf disk inoculum. $P$. ramorum zoospores were produced according to an established method (Parke and Lewis 2007) with dilute (one-third strength) V8 agar substituted for V8-corn meal agar. $P$. pini zoospores were produced according to Ochiai et al. (2011). Similar-aged rhododendron cultivar Catawbiense Boursault leaves were collected from plants maintained in a greenhouse at Oregon State University. Leaves were dipped into a zoospore suspension $\left(5 \times 10^{4}\right.$ zoospores $\left./ \mathrm{ml}\right)$ and incubated in a moist chamber at $20^{\circ} \mathrm{C}\left(P\right.$. ramorum) or $24^{\circ} \mathrm{C}(P$. pini $)$. After 2 weeks, 6-mm-diameter disks were removed from leaf lesions using a hole punch. The batch of leaf disks was thoroughly mixed. The presence of chlamydospores (P. ramorum) or oospores (P. pini) within leaf tissue was confirmed by microscopic observation of cleared leaves prior to use as inoculum (Phillips and Hayman 1970).

Experimental description. Five types of experiments were conducted. $P$. ramorum was tested in all experiments and $P$. pini was included in two experiments. Infested leaf disk inoculum containing chlamydospores (P. ramorum) or oospores (P. pini) was used because they closely resembled naturally occurring inoculum sources in nursery soil and they were the most heat-resistant propagules. Mesh bags ( 2 by $2 \mathrm{~cm}$ ), each containing five leaf disks, were made of plastic window screen material. Five replicated mesh bags per sampling period for each treatment were prepared. Temperature was recorded every $30 \mathrm{~min}$ with button temperature dataloggers (model DS1921G; Maxim Integrated Products Inc., San Jose, CA).

To assay recovery of Phytophthora spp., infested leaf disks were removed from the mesh bags and plated on Phytophthora-selective medium (PARPH) (Jeffers and Martin 1986) with a modified concentration of antibiotics (ampicillin at $200 \mathrm{mg} / \mathrm{liter}$, rifamycin at $10 \mathrm{mg} /$ liter, pentachloronitrobenzene at $66.7 \mathrm{mg} / \mathrm{liter}$, hymexazol at $25 \mathrm{mg} / \mathrm{liter}$, and Delvocid at $20 \mathrm{mg} / \mathrm{liter}$ ) (DSM, Delft, The Netherlands). Plates were incubated at $20.5^{\circ} \mathrm{C}$ and examined after 20 days for outgrowth of colonies of $P$. ramorum or $P$. pini.
Recovery was quantified as the frequency of leaf disks (out of five) with outgrowth into the medium, expressed as a percentage.

Inoculum survival at constant high temperature (first experiment). Survival of $P$. ramorum and $P$. pini inoculum was tested after exposure to three different temperatures $(35.5,38$, or $50^{\circ} \mathrm{C}$ ) in distilled water. Mesh bags with leaf disk inoculum were kept in distilled water at room temperature $\left(20.5^{\circ} \mathrm{C}\right)$ for $12 \mathrm{~h}$ to equilibrate the water potential, then transferred to water-filled beakers in growth chambers maintained at each temperature. All beakers were kept in moist chambers to minimize evaporation. Mesh bags were removed every $12 \mathrm{~h}$ for 35.5 and $38^{\circ} \mathrm{C}$ and every $30 \mathrm{~min}$ for $50^{\circ} \mathrm{C}$, and immediately placed in new water-filled beakers at room temperature to quickly cool. Recovery of the inoculum was determined as described below. The experiment was planned to continue until the inoculum was inactivated. The experiment was conducted twice.

Comparison of survival in intermittent versus constant heat regimes (second experiment). Recovery of $P$. ramorum inoculum was compared after exposure of the inoculum to constant heat or an intermittent heat regime consisting of an alternating cycle of high and low temperature. The total duration of exposure to high temperature required to inactivate the inoculum was compared between the constant and intermittent regime. Two trials were conducted (trial 1 and trial 2).

In trial 1 , conducted in distilled water, survival of $P$. ramorum inoculum after exposure to a constant heat regime $\left(36.5^{\circ} \mathrm{C}\right)$ was compared with survival in the intermittent heat regime $(24 \mathrm{~h}$ of exposure to high temperature followed by $12 \mathrm{~h}$ at $20.5^{\circ} \mathrm{C}$ per cycle). For every cycle, mesh bags were placed into distilled water previously equilibrated to each temperature to allow for rapid temperature adjustment. In the constant heat regime, inoculum mesh bags were removed from the growth chamber every $12 \mathrm{~h}$ and placed in water at room temperature to quickly cool. In the intermittent heat regime, inoculum bags were removed after each heat event and immediately placed in room temperature water as well. Recovery of the inoculum was determined as previously described. The trial was conducted twice. In trial 2, conducted in moistened soil to better simulate field conditions, the survival of $P$. ramorum was tested after exposure to a constant heat regime $\left(36.5^{\circ} \mathrm{C}\right)$ and an intermittent heat regime $(8 \mathrm{~h}$ at $36.5^{\circ} \mathrm{C}$ and $16 \mathrm{~h}$ at $20.5^{\circ} \mathrm{C}$ per cycle). Soil was collected from the Oregon State University Botany Farm and Field Lab, Corvallis. The soil was air dried, sieved through 2-mm mesh, and moistened with distilled water to achieve a soil moisture condition typical of field soil during solarization (Funahashi and Parke 2016). Soil was packed in small, lidded sample containers $\left(11.6 \mathrm{~cm}^{3}\right.$; Aqua Lab, Decagon Devices, Pullman, WA) with a mesh bag containing inoculum of $P$. ramorum. Bulk density of the soil was $1.46 \mathrm{~g} / \mathrm{cm}^{3}$ and the water potential was $-72 \mathrm{kPa}$, calculated with a water retention curve of the soil. Volumetric soil water content was $20.0 \%$. Samples were left at room temperature for $12 \mathrm{~h}$, then moved into a growth chamber. In the intermittent heat regime, samples were removed from the growth chamber and immediately replaced to quickly change the temperature to which the inoculum was exposed. Samples were taken out of the growth chamber every $8 \mathrm{~h}$ in the constant heat regime or after each heat event in the intermittent heat treatment, and then placed in a cold room $\left(4^{\circ} \mathrm{C}\right)$ to quickly cool until processing within a few days. Survival was determined after rinsing leaf disks free of soil, then plating them on PARPH, as described above. The trial was conducted once.

Inoculum damage from different intensities of sublethal heat (third experiment). Sublethal heat is defined here as heat that is of shorter duration or of lower temperature than lethal heat after which outgrowth from the inoculum does not occur. The intensity of sublethal heat was quantified as a percentage of the intensity of lethal heat. In a heat treatment with a single temperature, its heat intensity is defined as the percentage of the treatment duration out of the lethal duration. Thus, $100 \%$ heat intensity is the condition where inoculum loses its ability to grow out, and $50 \%$ heat intensity is half 
of the lethal heat duration. Inoculum damaged by a sublethal heat treatment was expected to survive less time in the subsequent survival assay at a certain temperature than nondamaged inoculum. Inoculum damage was quantified as the percent reduction in survival time in the subsequent survival assay compared with the survival time of nondamaged inoculum.

This experiment was designed to evaluate $P$. ramorum inoculum damage resulting from different durations of constant sublethal heat (Fig. 1A); therefore, it was conducted in distilled water instead of soil to avoid any potential effects of antagonistic soil microorganisms. Two trials (trial 1 and trial 2) were conducted at $35^{\circ} \mathrm{C}$, at which nondamaged inoculum was inactivated in approximately 84 to $96 \mathrm{~h}$ according to the results of our first and second experiment. In trial 1 , inoculum was exposed to heat treatment of $0,24,36$, or $48 \mathrm{~h}$ at $35^{\circ} \mathrm{C}$, cooled to $20.5^{\circ} \mathrm{C}$ for $12 \mathrm{~h}$, and then returned to $35^{\circ} \mathrm{C}$. Samples were then taken every $12 \mathrm{~h}$ and recovery was assessed as previously described. In trial 2, inoculum was exposed to $0,24,48$, or $72 \mathrm{~h}$ at $35^{\circ} \mathrm{C}$ but was otherwise the same as the first trial. Each trial was conducted once. Mesh bags were transferred between beakers of distilled water equilibrated to each temperature.

Damage from multiple sublethal heat events (fourth experiment). This experiment was designed to test whether the damage from a given intensity of sublethal heat was consistent at all stages of inactivation (Fig. 1B). Two trials (trial 1 and trial 2) were conducted, in which the inoculum was exposed to zero, one, two, or three cycles of sublethal heat treatment of $24 \mathrm{~h}$ followed by $12 \mathrm{~h}$ at $20.5^{\circ} \mathrm{C}$, then returned to the heat to determine the survival length. In the first trial, the sublethal heat treatment was $36.5^{\circ} \mathrm{C}$ but, in the second trial, it was lowered to $35^{\circ} \mathrm{C}$. Samples were taken every $12 \mathrm{~h}$ (five replications) and survival was assessed as described previously. Each trial was conducted once.

Field temperature regime simulation (fifth experiment). The last experiment was designed to test survival of $P$. ramorum and $P$. pini at a temperature regime that simulated field conditions during a 2013 solarization trial in San Rafael, CA (15-cm depth), where the inoculum survived longer than predicted. Mesh bags enclosing leaf disk inoculum were kept in distilled water in a growth chamber set to mimic the daily temperature regime in the field (Supplementary Fig. S1). Inoculum was removed every $24 \mathrm{~h}$ for 12 days and survival was assessed as described previously. Inoculum survival from this experiment was compared with the output from predictive models established below. The experiment was conducted twice.

Recovery curve fitting, model establishment, and the calculation of damage. All model fitting and statistical tests were conducted using $\mathrm{R}$ statistics software, version 3.1.2 (R Development Core Team 2014) at a $P<0.05$ level of significance. Probit models were fitted to recovery data of each treatment by using equations 1 and 2:

$$
\begin{aligned}
\Phi(x) & =\int_{-\infty}^{x} \frac{1}{\sqrt{2 \pi}} \exp \left(-u^{2} / 2\right) d u \\
\Phi^{-1}(y) & =\beta_{1} x+\beta_{2}
\end{aligned}
$$

where $\Phi(x)$ is error function, $\Phi^{-1}(y)$ is its inverse function, $\beta_{1}$ and $\beta_{2}$ are coefficients, $u$ is an integral real-variable, and $x$ and $y$ are "day" and "frequency of recovery", respectively. The probit model was selected because it has been used to describe thermal inactivation in many previous studies (Thomas and Mangan 1997). The heat duration to achieve $0.1 \%$ recovery $\left(\mathrm{LD}_{99.9}\right)$ was calculated for the data from the first, second, and fifth experiments to establish a conservative predictive model of inoculum survival and to evaluate the other results by comparing them to the model output. $\mathrm{LD}_{99.9}$ is likely to reflect model fitting errors with tail effects because $\mathrm{LD}_{99.9}$ changes significantly with a small change in $\beta_{1}$ or $\beta_{2}$ in the probit model. This leads to relatively large standard errors in $\mathrm{LD}_{99.9}$, masking the treatment effects. Therefore, regarding our minimum experimental resolution of $1 / 25(4 \%)$, the duration of exposure to heat to achieve $5 \%$ recovery $\left(\mathrm{LD}_{95}\right)$ was used for the remaining experiments to compare treatment effects more clearly without being interrupted by the relatively large standard errors.

The measured $\mathrm{LD}_{99.9}$ for each inoculum type from the different temperature treatments was used to determine parameters in the thermal inactivation (death) curve (log time versus temperature) model below to estimate $\mathrm{LD}_{99.9}$ in various temperatures for both inocula:

$$
\begin{aligned}
\ln \left(\operatorname{LD}_{99.9}\right)= & a+b \times \text { Inoculum }+c \times \text { Temp }+d \\
& \times \text { Inoculum } \times \text { Temp }
\end{aligned}
$$

where $\ln$ indicates natural logarithm, $a, b, c$, and $d$ are coefficients, Inoculum $=0$ for $P$. ramorum and 1 for $P$. pini, and Temp is temperature $\left({ }^{\circ} \mathrm{C}\right)$. $\mathrm{LD}_{99.9}$ was used to establish a conservative predictive model of inoculum survival. The thermal inactivation
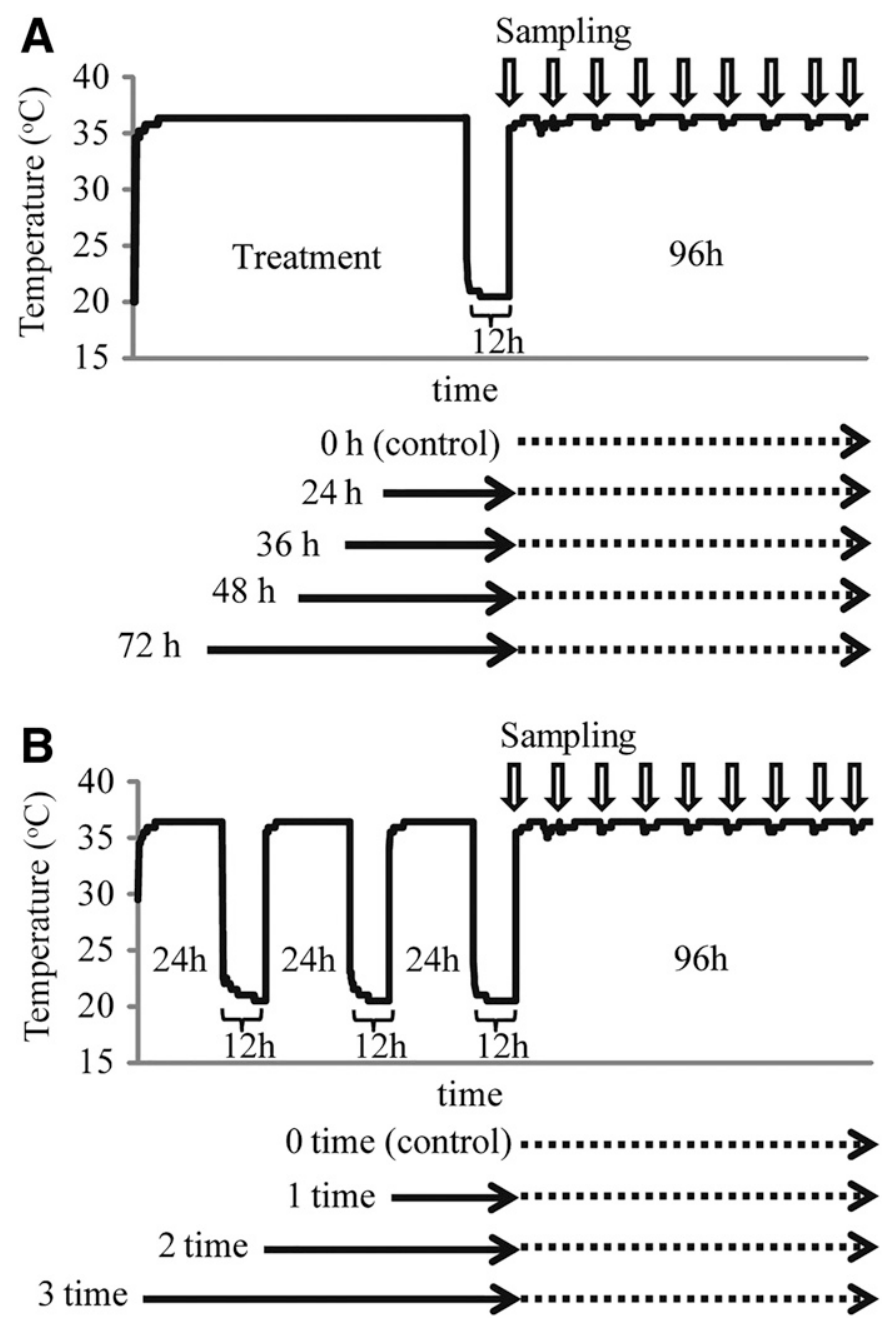

Fig. 1. Schematic diagram of the treatments in $\mathbf{A}$, the sublethal heat length experiment and $\mathbf{B}$, the multiple sublethal heat experiment to which Phytophthora ramorum inoculum was exposed. A, Inoculum was exposed to heat treatment of 0 (control), $24,36,48$, or $72 \mathrm{~h}$ at $35^{\circ} \mathrm{C}$, kept at $20.5^{\circ} \mathrm{C}$ for $12 \mathrm{~h}$, and then tested for survival at $35^{\circ} \mathrm{C}$ to compare the effects of the different sublethal heat length treatments. The experiment was conducted twice, except for the 36- and 72-h heat treatment. B, Inoculum was exposed to $24-\mathrm{h}$ heat treatment zero (control), one, two, or three times at $36.5^{\circ} \mathrm{C}$, with $12 \mathrm{~h}$ at $20.5^{\circ} \mathrm{C}$, and then tested for survival at $36.5^{\circ} \mathrm{C}$ to compare the effects of the different number of sublethal heat length treatments. The experiment was conducted twice, except that the temperature of the heat treatment and the measurement of survival in the second trial was $35^{\circ} \mathrm{C}$. Inoculum recovery was measured every $12 \mathrm{~h}$ after each treatment (five replications) to determine survival in both experiments. 
curve has been used in many previous studies (Pullman et al. 1981), and the full model was selected by model comparisons using analysis of variance tests in a general linear regression and evaluation through application of the Akaike information criterion (AIC) (Akaike 1973). AIC is a suitable model selection criterion for addressing which model will best predict the next sample (Aho et al. 2014). The AIC was calculated by:

$$
\mathrm{AIC}=n \ln R M S E+2 p
$$

where $n$ is the number samples, In indicates natural logarithm, RMSE is root-mean-square error, and $p$ the number of parameters used in the prediction. The model with the smallest AIC is best. Heat intensity rate $\left(r_{T}\right)$ at temperature $T$ was defined as:

$$
r_{T}\left(\text { day }^{-\mathrm{r}}\right)=1 / \mathrm{LD}_{99.9}
$$

A rate summation model was applied to calculate heat intensity for various temperature regimes:

$$
\text { Heat intensity }(\%)=100 \times \int r_{\mathrm{T}} d t
$$

where $d t$ is a unit time.

For the data from the third and fourth experiments of sublethal heat, $\mathrm{LD}_{95}$ for each treatment was calculated by fitting a probit model. $\mathrm{LD}_{95}$ of the control treatment in each experiment $\left(\mathrm{LD}_{95 \text {-control }}\right)$ was normalized to $100 \%$ of heat intensity, and $\mathrm{LD}_{95}$ of each treatment $\left(\mathrm{LD}_{95 \text {-treatment }}\right)$ was compared with each $\mathrm{LD}_{95 \text {-control }}$ to calculate the damage as the percent reduction in $\mathrm{LD}_{95}$ by each treatment:

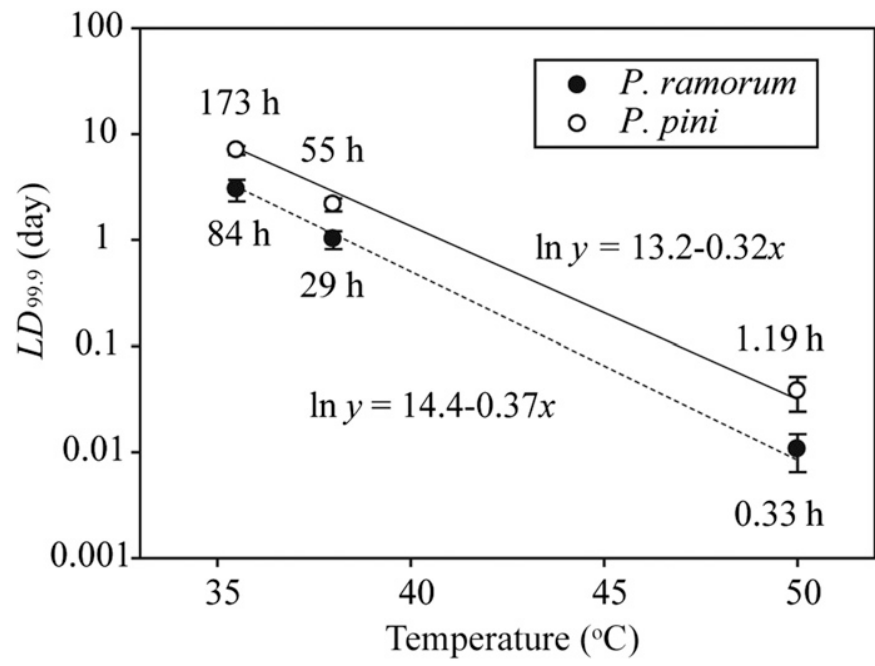

Fig. 2. Relationship between $99.9 \%$ lethal dose $\left(\mathrm{LD}_{99.9}\right)$ values and survival of Phytophthora ramorum (closed symbol) and $P$. pini (open symbol) after exposure to different temperatures $\left(35.5,38\right.$, and $\left.50^{\circ} \mathrm{C}\right)$. Regression lines derived from the general linear model are shown for P. ramorum (dotted line) and $P$. pini (solid line). Bars represent standard deviation.

TABLE 1. Summary of the output in the general linear regression model, 99.9\% lethal dose $=$ Intercept + Inoculum + Temperature + Temperature $\times$ Inoculum $^{\mathrm{a}}$

\begin{tabular}{lccrr}
\hline Parameter & Estimate & SE & $t$ value & $P$ value \\
\hline Intercept & 14.43 & 0.12 & 118.6 & $<\mathbf{0 . 0 0 1}$ \\
Inoculum & -1.20 & 0.28 & -4.3 & 0.051 \\
Temperature & -0.37 & 0.00 & -153.9 & $<\mathbf{0 . 0 0 1}$ \\
Temperature $\times$ Inoculum & 0.05 & 0.01 & 8.9 & $\mathbf{0 . 0 1 2}$ \\
\hline
\end{tabular}

a Data from two trials were pooled. The residual standard error (SE) was 0.191 with 2 degrees of freedom, and $R^{2}$ (coefficient of determination) was > 0.999. The significant $P$ values are shown in bold.
Damage $(\%)=\left(1-\mathrm{LD}_{95-\text { treatment }} / \mathrm{LD}_{95-\text { treatment }}\right) \times 100$

Heat intensity $(\%)$ of each sublethal heat treatment was calculated by the duration of the treatment $(L)$ divided by $\mathrm{LD}_{95 \text {-control }}$ :

$$
\text { Heat intensity }(\%)=\left(\mathrm{L} / \mathrm{LD}_{95} \text {-treatment }\right) \times 100
$$

A power function regression model was used to fit the relationship between the sublethal heat intensity and damage:

$$
\text { Damage }(\%)=[\text { Heat intensity }(\%)]^{a} / 100^{a-1}
$$

The coefficient $a$ was statistically tested if it was significantly different from 1 by using nonlinear regression analysis. If coefficient $a$ is 1 , damage is equal to heat intensity. Thus, $a>1$ shows a concave relationship and $a<1$ shows a convex relationship between damage and heat intensity.

The damage from multiple sublethal heat events was calculated with equation 7 , and linearity of the relationship between damage and repeated sublethal heat events was tested by regression model fitting.

\section{RESULTS}

Inoculum survival at constant high temperature (first experiment). Survival of $P$. ramorum and $P$. pini inoculum was tested after exposure to three different temperatures $(35.5,38$, or $50^{\circ} \mathrm{C}$ ) in distilled water. There was a significant negative relationship between increasing temperature and $\mathrm{LD}_{99.9}$ values for both $P$. ramorum and $P$. pini (Fig. 2). Temperature coefficients in the model were -0.37 for $P$. ramorum and -0.32 for $P$. pini. $P$. pini survived significantly longer at any temperature treatment than did $P$. ramorum (Fig. 2). The general linear regression model was applied and the summary of the output is shown (Table 1). In the full model, all parameters were highly significant, except for the Inoculum parameter $(P=0.051)$. Because the $P$ value is still relatively small and AIC of the full model $(-29.3)$ was smaller than the reduced model without the Inoculum parameter $(-17.4)$, the full model was selected as:

$$
\begin{aligned}
\operatorname{In}\left(\operatorname{LD}_{99.9}\right)= & 14.43+1.20 \times \text { Inoculum }-0.37 \times \text { Temp } \\
& +0.05 \times \text { Inoculum } \times \text { Temp }
\end{aligned}
$$

This model was used to calculate heat regimes in all other experiments.

Comparison of survival in intermittent versus constant heat regimes (second experiment). Recovery of $P$. ramorum inoculum was compared after exposure of the inoculum to constant heat or an intermittent heat. The regression coefficients with both intercept and slope in the fitted probit models were all significant in the experiment $(P<0.05)$. $P$. ramorum survived significantly longer in the intermittent heat regime $\left(\mathrm{LD}_{99.9}=113 \pm 19\right.$ confidence interval $[\mathrm{CI}] \mathrm{h})$ than in the constant heat regime $\left(\mathrm{LD}_{99.9}=48 \pm 7 \mathrm{CI}\right.$ h) in the trial with distilled water (Fig. 3). In the constant heat regime, calculated $\mathrm{LD}_{99.9}$ was within the range of values predicted by equation $10\left(\mathrm{LD}_{99.9}=50 \mathrm{~h}\right)$. Similarly, in the trial with moistened soil, $P$. ramorum survived longer in the intermittent heat regime $\left(\mathrm{LD}_{99.9}=96 \pm 10 \mathrm{CI} \mathrm{h}\right)$ than in the constant heat regime $\left(\mathrm{LD}_{99.9}=\right.$ $58 \pm 7$ CI h) (Supplementary Fig. S2). The calculated $\mathrm{LD}_{99.9}$ for the constant heat regime in soil did not significantly differ from the predicted value in equation $10\left(\mathrm{LD}_{99.9}=50 \mathrm{~h}\right)$ based on the initial experiments conducted in distilled water.

Inoculum damage from different intensities of sublethal heat (third experiment). This experiment evaluated $P$. ramorum inoculum damage resulting from different durations of constant sublethal heat. The longer sublethal heat treatments ( 48 and $72 \mathrm{~h}$ of exposure) significantly shortened the subsequent $P$. ramorum inoculum survival but there was no difference in subsequent survival length between $24 \mathrm{~h}$ of sublethal heat treatment and the control 
treatment (Supplementary Fig. S3). Only the result of the second trial was shown but the first trial resulted in a similar pattern. The inoculum damage and the intensity of each sublethal heat treatment were calculated in each trial separately. The relationship between inoculum damage and the intensity of sublethal heat was fitted with a power function nonlinear regression model:

$$
\text { Damage }(\%)=[\text { Heat intensity }(\%)]^{2.37} / 100^{1.37}
$$

The coefficient $a=2.4$ was significantly larger than $1(P<0.001)$, showing that the regression line was significantly concave from the 1:1 line. The concave shape of the relationship showed that the inoculum damage in the beginning of a single heat event was relatively small but increased rapidly by prolonged exposure to heat (Fig. 4A).

Damage from multiple sublethal heat events (fourth experiment). This experiment tested whether the damage from a given intensity of sublethal heat was consistent at all stages of inactivation. Every sublethal heat event significantly shortened the survival of $P$. ramorum inoculum (Supplementary Fig. S4). Only the result of the first trial was shown but the second trial resulted in a similar pattern. The inoculum damage by each treatment was calculated for each trial separately. The heat intensity of a single sublethal heat event was $56.0 \%$ in the first trial and $26.8 \%$ in the second trial. For both trials, a linear relationship between inoculum damage and repeated sublethal heat events were observed with significant first-order regression models (Fig. 4B, trial 1, $P=0.005$; trial 2, $P=0.005$ ). Relationships were considered to be linear because the second-order regression models did not significantly differ from the first-order regression model for each trial (trial $1, P=0.179$; trial $2, P=0.391$ ). The linear relationship assumes that the damage caused by a given intensity of sublethal heat is consistent at any stage of inactivation. The damage caused by a single sublethal heat event approximated the mathematical prediction calculated by the damage equation (equation 11). In trial 1, 17.2 $\pm 4.6 \mathrm{CI} \%$ damage was caused by $56.0 \%$ of heat intensity as opposed to the mathematical prediction of $25.3 \%$ (approximately 20.7 to $30.9 \%$ ), and $9.3 \pm 2.4 \mathrm{CI} \%$ damage in trial 2 was caused by $26.8 \%$ of heat intensity as opposed to the mathematical prediction of $4.4 \%$ (approximately 2.8 to $7.0 \%$ ). Therefore, the inoculum damage from each sublethal heat event was calculated by:

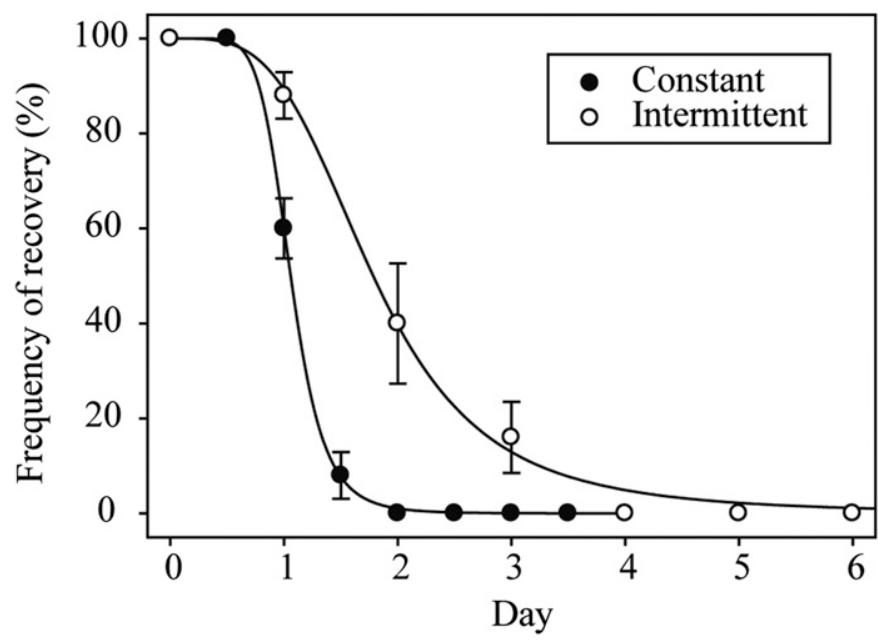

Fig. 3. Frequency of recovery (percent) of Phytophthora ramorum inoculum in distilled water during exposure to $36.5^{\circ} \mathrm{C}$ of constant heat treatment (filled circle) compared with recovery in intermittent heat treatment $\left(24 \mathrm{~h}\right.$ of $36.5^{\circ} \mathrm{C}$ and $12 \mathrm{~h}$ of $20.5^{\circ} \mathrm{C}$ ) (open circle). Bars represent standard error and regression lines by probit model are shown.

$$
\operatorname{Damage}_{i}(\%)=[\text { Heat intensity }(\%)]^{2.37} / 100^{1.37}
$$

where Damage ${ }_{i}$ and Heat intensity ${ }_{i}$ are the damage and the heat intensity, respectively, of $i$ th sublethal heat event. Total damage was calculated as cumulative damage of all sublethal heat events by:

$$
\text { Total Damage }(\%)=\sum \text { Damage }_{i}
$$

Field temperature regime simulation (fifth experiment). The last experiment tested survival of $P$. ramorum and $P$. pini at a simulated field temperature regime to evaluate the model, including a correction for an intermittent heat regime. The recovery of both $P$. ramorum and $P$. pini subjected to the simulated field temperature regime indicated that $P$. pini survived significantly longer than P. ramorum, as expected ( $P$. ramorum: $\mathrm{LD}_{99.9}=138 \pm 12 \mathrm{CI} \mathrm{h}$ and P. pini: $\mathrm{LD}_{99.9}=292 \pm 18 \mathrm{CI}$ h) $($ Fig. $5 \mathrm{~A})$. The measured daily
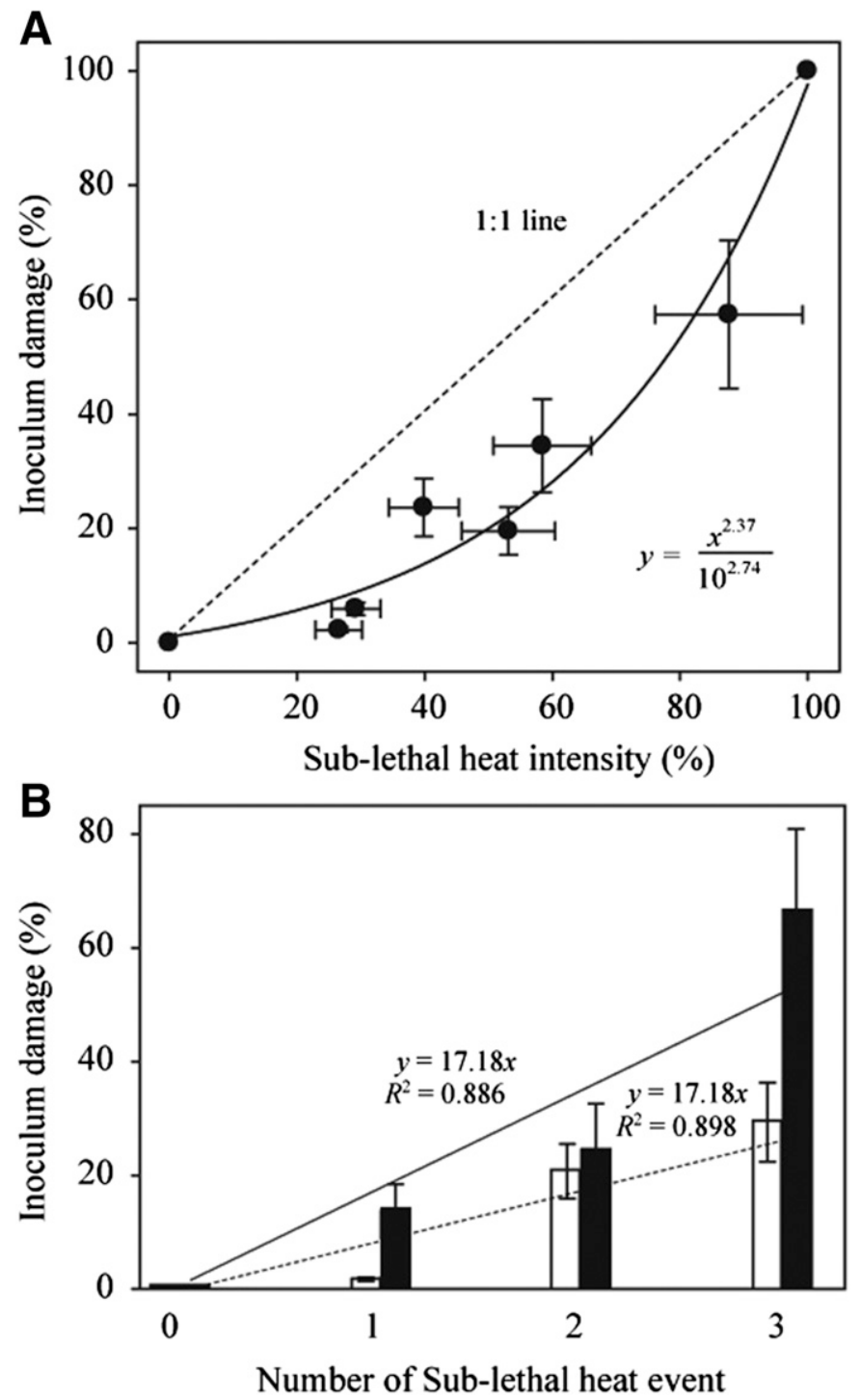

Fig. 4. Relationships between A, different sublethal heat intensity (percent) or B, the number of sublethal heat events and Phytophthora ramorum inoculum damage (percent). A, The power function nonlinear regression line is shown as solid line. Dotted line shows a 1:1 line. Residual standard error was 0.169, with 7 degrees of freedom. B, Results are shown for trial 1, with $56.0 \%$ heat intensity of a single sublethal heat event (black bar), and trial 2, with $26.8 \%$ heat intensity of a single sublethal heat event (white bar). The first-order regression lines are shown (trial $1=$ solid line and trial $2=$ dotted line). Heat intensity is defined as the percentage of the treatment duration out of the lethal duration. Bars represent standard deviation. 
temperature regime was imported into the model using equations 10,5 , and 6 without a correction for the intermittent regime, and output of heat intensities were plotted with inoculum recovery for each sampling period (Fig. 5B). The heat intensity at $\mathrm{LD}_{99.9}$ was calculated to be significantly greater than $100 \%$ (P. ramorum: $\mathrm{LD}_{99.9}=265.0 \pm 25.3 \mathrm{CI} \%$ and P. pini: $\left.\mathrm{LD}_{99.9}=281.7 \pm 18.0 \mathrm{CI} \%\right)$.
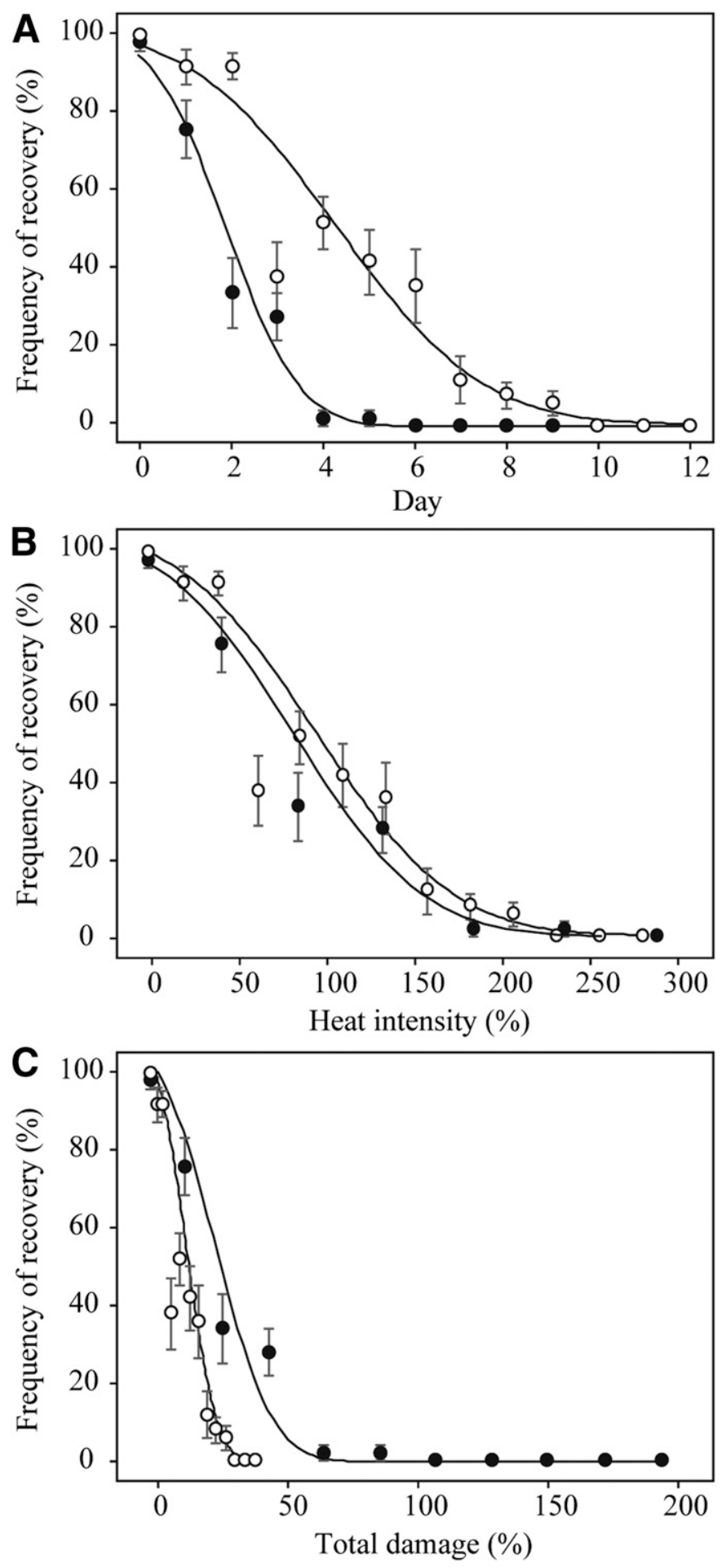

Fig. 5. A, Observed frequency of recovery of Phytophthora ramorum (closed circle) and $P$. pini (open circle) inoculum during a simulated field temperature regime. B, Relationship between observed frequency of recovery of each inoculum and heat intensity calculated from the model without the intermittent heat regime correction. C, Relationship between observed recovery of each inoculum and calculated total inoculum damage from the model with intermittent heat regime correction. Bars represent standard error and regression lines with probit model are shown.
To take the intermittent heat regime into account, the heat intensity of each day was recalculated with the damage equation (equation 12) to reflect the actual inoculum damage, and the total inoculum damage was plotted for each sampling period (Fig. 5C). The same equations were used for both $P$. ramorum and $P$. pini. The model prediction was significantly improved and calculated damage at $\mathrm{LD}_{99.9}$ was less than $100 \%$ for both $P$. ramorum $\left(\mathrm{LD}_{99.9}=92.5 \pm 9.6 \mathrm{CI} \%\right)$ and $P$. pini $\left(\mathrm{LD}_{99.9}=38.2 \pm 2.5 \mathrm{CI} \%\right)$, although it was overcorrected for $P$. pini.

\section{DISCUSSION}

Our experiments demonstrated significantly longer survival of infested leaf inoculum of $P$. ramorum subjected to the same total number of hours of high temperature in intermittent heat than in constant heat (second experiment). Similar trends were observed in soil and in water. Intermittent heat apparently causes less physiological damage to the inoculum than exposure to constant heat. Nonlinear damage accumulation was observed in continuous heat and multiple sublethal heat events, resulting in development of a more accurate mathematical model to predict thermal inactivation under field conditions for both $P$. ramorum and $P$. pini inoculum (third, fourth, and fifth experiments).

Probit models were successfully fitted to all recovery data in assays using infested leaf disk inoculum, with significant coefficients of slopes and intercepts. This shows that the survival period of leaf disk inoculum follows a normal distribution. Leaf disk inoculum contains both hyphae and survival structures such as chlamydospores ( $P$. ramorum) and oospores $(P$. pini). A mechanism at the molecular level behind the death of the inoculum (such as the inactivation of certain vital enzymes or denaturing of DNA) may differ among cell types (Peleg and Cole 1998; van Boekel 2002). However, measured LD are likely to reflect the response of the most heat-resistant spores. The effect of temperature on inoculum survival was successfully expressed with the semilogarithm regression model (Table 1). This is consistent with many previous studies that described a linear relationship between logarithms of $\mathrm{LD}_{90}(\mathrm{D}$ value) and temperatures for Verticillium dahliae, Pythium ultimum, Thielaviopsis basicola, Rhizoctonia solani (Pullman et al. 1981), and E. coli (Fujikawa and Itoh 1998). The longer survival of Phytophthora pini as compared with $P$. ramorum is also consistent with previous studies (Jung and Burgess 2009; Werres et al. 2001).

Other researchers have reported that intermittent heat was less effective in killing plant pathogens than was constant heat. For example, sclerotia of Sclerotinia sclerotiorum (Porter 1991), and chlamydospores of $P$. nicotianae (Coelho et al. 2000) required longer exposure to intermittent heat than to constant heat to become inactivated. A similar difference in inoculum survival between intermittent and constant heat regimes was observed in soil for $P$. ramorum (second experiment). The water potential of the soil used in the experiment was typical of field conditions under solarization after initial irrigation $(-72 \mathrm{kPa})$. Therefore, the observed difference between intermittent and constant heat regimes in laboratory conditions is also likely to be significant under field conditions. The nonlinear, concave increase of inoculum damage during continuous heat treatment (third experiment) indicates an increasing rate of inoculum damage accumulation. It is unknown whether the curves would be the same shape under all temperature and water potential conditions. Damage caused by multiple heat events appeared to be constant (fourth experiment), although it is difficult to conclude definitively because only three heat cycles were tested. However, this allowed stepwise calculation of damage accumulation through multiple sublethal heat events to better predict inoculum survival. The damage concept explains the extended inoculum survival because less damage actually occurs in each sublethal heat event than would be expected by heat intensity alone. A model including a correction for intermittent heat regime utilizing the damage equation significantly improved the prediction 
of thermal inactivation under a simulated field temperature condition (fifth experiment).

The low temperature threshold that separates a heat regime into multiple sublethal heat regimes is unknown. Russell (2003) reviewed lethal effects of heat on the physiology and structure of bacterial vegetative cells and spores; proteins and enzymes are considered to be the major targets of heat inactivation for both types of cells. There is a numerical correlation between the thermodynamic parameters of protein denaturation and the observed death rates of various organisms. The low temperature threshold and the increasing inoculum damage rate during continuous heat treatment probably reflect the kinetics of these inactivation mechanisms. It is also unknown how different low-temperature regimes cause different intermittent effects on pathogen survival. Longer periods of low temperature might trigger chlamydospore or oospore germination (Tooley and Carras 2011) and may affect thermotolerance through a different mechanism. Recovery under simulated field conditions confirmed that an intermittent heat regime correction with the damage equation is important (fifth experiment). The model without the intermittent heat regime correction predicted that $52 \mathrm{~h}$ of the simulated regime was enough to inactivate $P$. ramorum inoculum even though it actually required $138 \mathrm{~h}$. Likewise, the model without an intermittent heat regime correction predicted that $104 \mathrm{~h}$ of the simulated regime was enough to inactivate $P$. pini inoculum even though it actually required $292 \mathrm{~h}$. The model including the intermittent heat regime correction significantly improved the prediction for $P$. ramorum but somewhat overcorrected the damage to $P$. pini, possibly indicating a different response to intermittent heat than for $P$. ramorum. It is unclear whether different amounts of damage affect pathogenicity of surviving inoculum. Because delayed mortality (Assaraf et al. 2002) and decreased germination and pathogenicity (Arora et al. 1996) were reported for Fusarium oxysporum induced by the sublethal heat treatment, further study is necessary.

It is beneficial to use intermittent heat in controlled studies of thermal inactivation to better estimate conditions necessary to control plant pathogens by soil solarization (Coelho et al. 2000). However, it is difficult to employ cycling temperature treatments due to all the various possible temperature regimes, with different combinations of high and low temperature and different durations of each temperature. If the same structure of the damage equation (equation 9) could be used for different organisms, it would be easier to establish an accurate predictive model for each organism. Because the damage equation has only one coefficient to determine, technically, one test regime would be enough for this purpose.

In conclusion, this study demonstrated that intermittent heat is less damaging to inoculum of two Phytophthora spp. than is constant heat. The damage rate during continuous heat is not constant but rapidly increases. Therefore, corrections to the model are required for every sublethal heat event to accurately predict pathogen inactivation in fluctuating regimes. The same damage equation can be applied to each sublethal heat event because the achieved damage rate appeared to be similar at all stages of inactivation. However, more detailed studies are necessary to conclusively demonstrate that the rate of damage accumulation is constant over multiple heat events.

\section{ACKNOWLEDGMENTS}

We thank E. Peterson for help in conducting the fifth experiment.

\section{LITERATURE CITED}

Aho, K., Derryberry, D., and Peterson, T. 2014. Model selection for ecologists: The worldviews of AIC and BIC. Ecology 95:631-636.

Akaike, H. 1973. Information theory and an extension of maximum likelihood principle. Pages 267-281 in: Second Int. Symp. Inf. Theory. B. N. Petrov and F. Csaki, eds. Akademia Kiado, Budapest, Hungary.
Arora, D. K., Pandey, A. K., and Srivastva, A. K. 1996. Effects of heat stress on loss of C, germination and pathogenicity from chlamydospores of Fusarium oxysporum f. sp. ciceri. Soil Biol. Biochem. 28:399-407.

Assaraf, M. P., Ginzburg, C., and Katan, J. 2002. Weakening and delayed mortality of Fusarium oxysporum by heat treatment: Flow cytometry and growth studies. Phytopathology 92:956-963.

Chellemi, D. O., Olson, S. M., and Mitchell, D. J. 1994. Effects of soil solarization and fumigation on survival of soilborne pathogens of tomato in northern Florida. Plant Dis. 78:1167-1172.

Coelho, L., Mitchell, D. J., and Chellemi, D. O. 2000. Thermal inactivation of Phytophthora nicotianae. Phytopathology 90:1089-1097.

Corradini, M. G., and Peleg, M. 2006. On modeling and simulating transitions between microbial growth and inactivation or vice versa. Int. J. Food Microbiol. 108:22-35.

Dyer, A. T., Windels, C. E., Cook, R. D., and Leonard, K. J. 2007. Survival dynamics of Aphanomyces cochlioides oospores exposed to heat stress. Phytopathology 97:484-491.

Fujikawa, H., and Itoh, T. 1998. Thermal inactivation analysis of mesophiles using the Arrhenius and Z-value models. J. Food Prot. 61:910-912.

Funahashi, F., and Parke, J. L. 2016. Effects of soil solarization and Trichoderma asperellum on soilborne inoculum of Phytophthora ramorum and Phytophthora pini in container nurseries. Plant Dis. 100:438-443.

Gamliel, A., and Katan, J. 2012. Soil Solarization: Theory and Practice. American Phytopathological Society Press, St. Paul, MN.

Goss, E. M., Larsen, M., Chastagner, G. A., Givens, D. R., and Grünwald, N. J. 2009. Population genetic analysis infers migration pathways of Phytophthora ramorum in US nurseries. PLoS Pathog. 5:e1000583.

Hong, C., Gallegly, M. E., Richardson, P. A., and Kong, P. 2011. Phytophthora pini Leonian resurrected to distinct species status. Mycologia. 103:351-360.

Hong, C., Richardson, P. A., and Kong, P. 2008. Pathogenicity to ornamental plants of some existing species and new taxa of Phytophthora from irrigation water. Plant Dis. 92:1201-1207.

Jeffers, S. N., and Martin, S. B. 1986. Comparison of two media selective for Phytophthora and Pythium species. Plant Dis. 70:1038-1043.

Jung, T., and Burgess, T. I. 2009. Re-evaluation of Phytophthora citricola isolates from multiple woody hosts in Europe and North America reveals a new species, Phytophthora plurivora sp. nov. Persoonia 22:95-110.

Lopez-Herrera, C. J., Perez-Jimenez, R. M., Basallote-Ureba, M. J., Zea Bonilla, T., and Melero-Vara, J. M. 1997. Effect of soil solarization on the control of Phytophthora root rot in avocado. Plant Pathol. 46:329-340.

Lopez-Herrera, C. J., Verdu-Valiente, B., and Melero-Vara, J. M. 1994. Eradication of primary inoculum of Botrytis cinerea by soil solarization. Plant Dis. 78:594-597.

Ochiai, N., Dragila, M. I., and Parke, J. L. 2011. Pattern swimming of Phytophthora citricola zoospores: An example of microbial bioconvection. Fungal Biol. 115: 228-235.

Olson, H. A., Jeffers, S. N., Ivors, K. L., Steddom, K. C., Williams-Woodward, J. L., Mmbaga, M. T., Benson, D. M., and Hong, C. X. 2013. Diversity and mefenoxam sensitivity of Phytophthora spp. associated with the ornamental horticulture industry in the Southeastern United States. Plant Dis. 97:86-92.

Parke, J. L., Knaus, B. J., Fieland, V. J., Lewis, C., and Grünwald, N. J. 2014. Phytophthora community structure analyses in Oregon nurseries inform systems approaches to disease management. Phytopathology. 104: 1052-1062.

Parke, J. L., and Lewis, C. 2007. Root and stem infection of rhododendron from potting medium infested with Phytophthora ramorum. Plant Dis. 91: 1265-1270.

Peleg, M., and Cole, M. B. 1998. Reinterpretation of microbial survival curves. Crit. Rev. Food Sci. Nutr. 38:353-380.

Peleg, M., and Penchina, C. M. 2000. Modeling microbial survival during exposure to a lethal agent with varying intensity. Crit. Rev. Food Sci. Nutr. 40:159-172.

Phillips, J. M., and Hayman, D. S. 1970. Improved procedures for clearing roots and staining parasitic and vesicular-arbuscular mycorrhizal fungi for rapid assessment of infection. Trans. Br. Mycol. Soc. 55:158-161, IN16-IN18.

Porter, I. J. 1991. Factors which influence the effectiveness of solarization for control of soilborne fungal pathogens in South Eastern Australia. Ph.D. dissertation, La Trobe University, Bundoora, Victoria, Australia.

Pullman, G. S., DeVay, J. E., and Garber, R. H. 1981. Soil solarization and thermal death: A logarithmic relationship between time and temperature for four soilborne plant pathogens. Phytopathology 71:959-964.

R Development Core Team. 2014. R: A Language and Environment for Statistical Computing. R version 3.1.2. Online publication. http://www.Rproject.org

Russell, A. D. 2003. Lethal effects of heat on bacterial physiology and structure. Sci. Prog. 86:115-137.

Sapru, V., Smerage, G. H., Teixeira, A. A., and Lindsay, J. A. 1993. Comparison of predictive models for bacterial spore population resources to sterilization temperatures. J. Food Sci. 58:223-228. 
Sasanelli, N., and Greco, N. 2000. Formulation of a model to relate nematode populations with exposure times to a range of temperatures. Acta Hortic. 532:131-136.

Shlevin, E., Saguy, I. S., Mahrer, Y., and Katan, J. 2003. Modeling the survival of two soilborne pathogens under dry structural solarization. Phytopathology 93:1247-1257.

Tamietti, G., and Valentino, D. 2001. Soil solarization: A useful tool for control of Verticillium wilt and weeds in eggplant crops under plastic in the Po valley. J. Plant Pathol. 83:173-180.

Thomas, D. B., and Mangan, R. L. 1997. Modeling thermal death in the Mexican fruit fly (Diptera: Tephritidae). J. Econ. Entomol. 90:527-534.

Tooley, P. W., and Carras, M. M. 2011. Enhanced recovery of Phytophthora ramorum from soil following 30 days of storage at $4^{\circ} \mathrm{C}$. J. Phytopathol. 159: 641-643.

USDA-APHIS. 2015. Phytophthora ramorum program updates. Online publication. United States Department of Agriculture Animal and Plant Health Inspection Service (USDA-APHIS). https://www.aphis.usda.gov/ aphis/ourfocus/planthealth/plant-pest-and-disease-programs/pests-and-diseases/phytophthora-ramorum/ct_updates

Usmani, S. M. H., and Ghaffar, A. 1986. Time temperature relationships for the inactivation of sclerotia of Sclerotium oryzae. Soil Biol. Biochem. 18: 493-496.

van Boekel, M. 2002. On the use of the Weibull model to describe thermal inactivation of microbial vegetative cells. Int. J. Food Microbiol. 74: 139-159.

Walkey, D. G. A., and Freeman, G. H. 1977. Inactivation of cucumber mosaic virus in cultured tissues of Nicotiana rustica by diurnal alternating periods of high and low temperature. Ann. Appl. Biol. 87:375-382.

Weibull, W. 1951. A statistical distribution of wide applicability. J. Appl. Mech. 18:293-297.

Werres, S., Marwitz, R., Veld, W., De Cock, A., Bonants, P. J. M., De Weerdt, M., Themann, K., Ilieva, E., and Baayen, R. P. 2001. Phytophthora ramorum sp. nov. a new pathogen on Rhododendron and Viburnum. Mycol. Res. 105:1155-1165. 